\title{
RESEARCH
}

Open Access

\section{Survival benefit of surgical resection after first-line triplet chemotherapy and bevacizumab in patients with initially unresectable metastatic colorectal cancer}

Mahmoud A. Elshenawy ${ }^{1,2}$, Ahmed Badran ${ }^{1,3}$, Ali Aljubran ${ }^{1}$, Ahmed Alzahrani ${ }^{1}$, M. Shahzad Rauf ${ }^{1}$, Abdelmoneim Eldali ${ }^{4}$ and Shouki Bazarbashi ${ }^{1 *}$ (D)

Abstract: Background: Surgical resection of metastatic disease in patients with initially non-resectable colorectal cancer (CRC) has improved overall survival. Intensified chemotherapy regimens have increased the probability of converting unresectable metastasis to resectable. Here, we report the result of combining intensive chemotherapy (triplet) and surgical resection of metastatic lesions in patients with metastatic CRC.

Patients and methods: Patients with unresectable metastatic CRC were enrolled in phase I/I trial of triplet chemotherapy consisting of capecitabine, oxaliplatin, irinotecan, and bevacizumab. Patients were given 5-8 cycles induction chemotherapy of the above regimen followed by maintenance capecitabine and bevacizumab until disease progression, unacceptable toxicity, or patient request. All patients were assessed at a multidisciplinary conference for possible surgical resection of their metastatic disease at the time of inclusion in the trial and 2 monthly intervals thereafter.

Patients who underwent RO resection of their metastatic disease received adjuvant oxaliplatin and capecitabine to complete a total of 6 months of chemotherapy.

Results: Fifty-three patients were enrolled. The median age was 52 years (range 23-74), 29 (55\%) were males, ECOG PS 0-1 was $13(66 \%), 11$ (42\%) had a right-sided tumor, 29 (55\%) had resection of their primary tumor, 22 (42\%) had a single metastatic site, and 8 (15.1\%) had a liver-limited disease.

Thirteen patients (24.5\%) underwent surgical resection of residual metastatic disease +/- the primary tumor with 10 (18.9\%) of them were RO.

The surgical group had a higher incidence of males compared to the non-surgical group (69.3\% vs $47.2 \%, p=0.2)$, equal performance status, lower median number of metastatic sites (1 vs $2, p=0.09$ ), higher mutant Kras ( $53.8 \%$ vs $34.2 \%, p=0.3$ ), and higher response rate $(84.6 \%$ vs $56.2 \%, p=0.3)$.

With a median follow-up duration of 89 months, the median PFS for the whole group was 16.1 months [95\% confidence interval (Cl) 9.1-20] and the median OS was 28.2 months (95\% Cl 22.5-53.3).

The median PFS for the surgery group was 18.9 months ( $95 \%$ Cl 12.6-not reached) compared to 9.6 months (95\% Cl 7.018.3) for the non-surgical group, log-rank $p=0.0165$. The median OS for both groups was not reached $(95 \% \mathrm{Cl} 53.3-$ not (Continued on next page)

\footnotetext{
* Correspondence: bazarbashi@gmail.com

${ }^{1}$ Medical Oncology Section, Oncology Centre, King Faisal Specialist Hospital and Research Centre, PO Box 3354, Riyadh 11211, Saudi Arabia

Full list of author information is available at the end of the article
}

(c) The Author(s). 2020 Open Access This article is licensed under a Creative Commons Attribution 4.0 International License, which permits use, sharing, adaptation, distribution and reproduction in any medium or format, as long as you give appropriate credit to the original author(s) and the source, provide a link to the Creative Commons licence, and indicate if changes were made. The images or other third party material in this article are included in the article's Creative Commons licence, unless indicated otherwise in a credit line to the material. If material is not included in the article's Creative Commons licence and your intended use is not permitted by statutory regulation or exceeds the permitted use, you will need to obtain permission directly from the copyright holder. To view a copy of this licence, visit http://creativecommons.org/licenses/by/4.0/ The Creative Commons Public Domain Dedication waiver (http://creativecommons.org/publicdomain/zero/1.0/) applies to the data made available in this article, unless otherwise stated in a credit line to the data. 


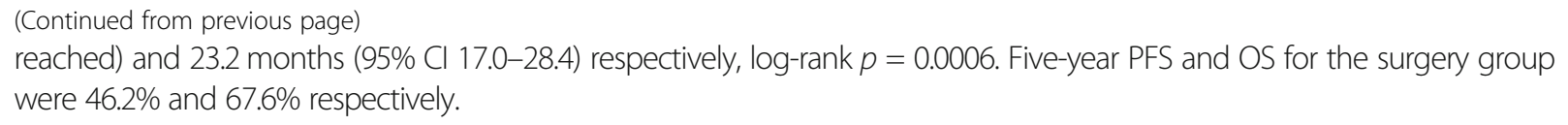

Conclusions: Patients with unresectable metastatic CRC and fit for triplet chemotherapy should have the benefit of combining this intensified regimen and surgical resection of their metastatic disease if possible.

Trial registration: Clinicaltrials.gov, NCT01311050, registered March 6, 2011, retrospectively registered.

Keywords: Colorectal cancer, Triplet chemotherapy, FOLFOXIRI-Bevacizumab, Surgery

\section{Introduction}

Colorectal carcinoma (CRC) is the third most common malignancy worldwide and the second most common cause of cancer-related death in men and third in female [1]. A significant percentage of patients have metastatic disease at initial presentation, with lung and liver being the most common sites of metastasis. Most of these patients have unresectable metastatic lesions, rendering the disease incurable [2]. Synchronous liver metastases have been reported in approximately $25 \%$ of patients diagnosed initially as colorectal cancer, while approximately 50\% develop liver metastases during their disease course [3].

Chemotherapy has been proven to improve survival in patients with unresectable metastatic CRC.

The 5-year survival rate in patients with unresectable metastatic disease is close to $10-20 \%$ [4-7].

Triplet chemotherapy regimens combining fluoropyrimidines, oxaliplatin, and irinotecan with or without biologics have shown improved efficacy compared to doublets with higher response rate, longer progression, and overall survival [8-10].

Surgical resection of metastatic disease in patients with initially non-resectable metastasis has shown improved overall survival compared to those who could not undergo resection in many retrospective series. Most of the published reports have evaluated the benefit of liver resection in such circumstances [11, 12]; however, resection of nonliver metastasis including peritonectomy with or without hyperthermic intraperitoneal chemotherapy (HIPEC) has also shown improved survival compared to no surgery in both single-arm and randomized trials [13-15].

The probability of converting unresectable metastasis to resectable has been shown to be more likely with triplet chemotherapy than with the standard doublet regimens [8, 16-19]. Most of these trials have concentrated on resection of liver metastasis.

We previously published the results of our phase I/II trial of a triplet consisting of capecitabine, oxaliplatin, and irinotecan with bevacizumab in patients with advanced CRC [20].

Here, we report the post hoc analysis of the efficacy of combining intensive chemotherapy (triplet) and surgical resection of metastatic lesions in the above cohort of patients.

\section{Methods \\ Study design}

The present report represents a post hoc analysis of the previously published phase I/II trial of the triplet therapy in patients with unresectable metastatic or locally advanced colorectal cancer with analysis of the results in patients who underwent surgical resection.

\section{Patients}

Patients with metastatic CRC not amenable to surgical resection were enrolled in a phase I/II trial of triplet chemotherapy consisting of capecitabine, oxaliplatin, irinotecan, and bevacizumab [20]. Inclusion criteria included age more than 18 years, histologically confirmed CRC adenocarcinoma, no prior chemotherapy or targeted therapy for metastatic disease, Eastern Cooperative Oncology Group performance status (ECOG PS) 0-2, measurable disease as defined by response evaluation criteria in solid tumors (RECIST) V1.1 [21], and adequate organ function (absolute neutrophil count (ANC) $\geq 1.5 \times 10^{9} / \mathrm{l}$, platelet count $\geq 100 \times 10^{9} / \mathrm{l}$, normal serum bilirubin, serum transaminases $\leq 2.5$ times the upper limits of normal (ULN), normal serum creatinine, and urine dipstick for proteinuria $\leq$ $2+)$. Patients who had prior adjuvant oxaliplatin or fluoropyrimidine chemotherapy were eligible if the last chemotherapy was $\geq 12$ months. Patients were considered ineligible if they had any of the following criteria: central nervous system metastasis, prior malignancy within 5 years (except for adequately treated non-melanoma skin cancer or in situ cervical cancer), sever cardiovascular dysfunction, bleeding diathesis, major surgery within 28 days of starting therapy, active infection, uncontrolled hypertension, pregnancy or breastfeeding, and prior history of dihydropyrimidine deficiency.

\section{Treatment}

The phase I part of the trial has been described earlier in the previous publication [20]. Based on the phase I part, the recommended doses for the phase II were capecitabine $1000 \mathrm{mg} / \mathrm{m}^{2}$ orally on days 1 to 14 , oxaliplatin $130 \mathrm{mg} / \mathrm{m}^{2}$, irinotecan $150 \mathrm{mg} / \mathrm{m}^{2}$, and bevacizumab at $7.5 \mathrm{mg} / \mathrm{kg}$ of body weight, all on D1 of each cycle. Cycles were repeated every 21 days. Patients were given induction chemotherapy of the above regimen for 5-8 cycles 
followed by maintenance capecitabine and bevacizumab at the above doses till disease progression or unacceptable toxicity. All patients were assessed at a multidisciplinary conference for possible surgical resection of their metastatic disease at the time of inclusion in the trial and at 2 monthly intervals. Surgical resectability was at the discretion of the operating surgeon and according to standard surgical procedures. Patients with retroperitoneal lymph nodes were considered unresectable.

Patients who underwent R0 resection of their metastatic disease received adjuvant oxaliplatin and capecitabine to complete a total of 6 months of chemotherapy. Radiation therapy was not given in the pre- or postoperative setting.

\section{Statistics and efficacy endpoints}

The statistical design of the phase I and II parts of this study was described earlier [20]. The number of patients planned for the phase II part of the trial was 46 . All patients were assessed for response according to RECIST criteria V1.1 [21] by CT scans or MRI performed after the second, fifth, and eighth cycles of chemotherapy and every 2 months thereafter.

Progression-free survival (PFS) was calculated from the date of starting chemotherapy to the date of first documented disease progression, recurrence, or death from any cause. Overall survival (OS) was calculated from the start of chemotherapy to date of last follow-up or death from any cause. Tabulation and statistics were performed in the SAS statistical software application (version 9.4: SAS Institute, Cary, NC, USA). The Kaplan-Meier method was used to calculate PFS and OS. Calculation of $p$ values used the log-rank test, and results were considered statistically significant if $p$ is equal to or less than 0.05 . The chisquare test was used to calculate the $p$ value for the different factors between both groups.

\section{Results}

\section{Patients' characteristics}

A total of 53 patients with metastatic or locally advanced unresectable CRC were enrolled on a phase I/II trial of combination chemotherapy with capecitabine, oxaliplatin, irinotecan, and bevacizumab (6 on the phase I part and 47 on the phase II part). Patients' characteristics are illustrated in Table 1. Eight (15.1\%) patients had liver-limited disease (LLD). Thirteen patients (24.5\%) underwent surgical resection of residual metastatic disease $+/-$ the primary tumor with 10 (18.9\%) of them were R0. The other forty patients were deemed unresectable.

The characteristics of the 13 patients are illustrated in Table 2. Ten of them had synchronous metastasis, and 3 were metachronous. The surgical group had a higher incidence of males compared to non-surgical group (69.3\% vs $47.2 \%, p=0.2$ ), equal performance status, lower median number of metastatic sites ( 1 vs $2, p=0.09$ ), higher mutated Kras $(53.8 \%$ vs $34.2 \%, p=0.3)$, and higher response rate $(84.6 \%$ vs $56.2 \%, p=0.3)$, Table 3 . The type of surgical procedure performed in each of the 13 patients in addition to significant surgical complications is listed in Table 4.

The median number of triplet chemotherapy cycles given prior to surgery was 5 (range 2-8). The median number of chemotherapy cycles given prior to surgery (induction triplet therapy + maintenance capecitabine and bevacizumab) was 9 (range 2-20). The median duration from the start of chemotherapy to surgery was 311 days (range 70-552).

\section{Efficacy analysis}

Forty-five patients of the total 53 patients were evaluable for response, 2 (4.4\%) patients achieved complete response (CR), and $27(60 \%)$ achieved partial response (PR) for overall response rate (ORR) of 64\%. Sixteen (31\%) patients achieved stable disease (SD). The disease control rate was $95 \%$. Eight patients were not evaluable

Table 1 Characteristics of 53 patients treated with the triplet chemotherapy regimen

Median age (range) (y) $52(23-74)$

Male/female [number (\%)] $29(55) / 24(45)$

ECOG performance status [number (\%)]

0

$7(13)$

1

$35(66)$

2

$11(21)$

Primary tumor site [number (\%)]

Colon

$23(40)$

Rectosigmoid

$21(36)$

Rectum

9(15)

Prior surgery for primary tumor [number (\%)]

$29(55)$

Prior adjuvant chemotherapy [number (\%)]

$6(11)$

Prior radiotherapy [number (\%)]

0

Number of metastasis sites [number (\%)]

Single

$22(42)$

Multiple sites

$31(58)$

Metastasis sites [number (\%)]

Liver

$35(66.0)$

Lung

$22(41.5)$

Lymph nodes

$21(39.6)$

Peritoneum

$14(26.4)$

K-ras [number (\%)]

Wild-type

$20(37.0)$

Mutated

$20(37.0)$

Unknown

$13(26.0)$

$Y$ years 
Table 2 Characteristics of patients who underwent surgical resection $(n=13)$

\begin{tabular}{|c|c|}
\hline & No. (\%) \\
\hline \multicolumn{2}{|l|}{ Age (years) } \\
\hline Median & 50.5 (IQR 41-57) \\
\hline \multicolumn{2}{|l|}{ Gender } \\
\hline Male & $9(69.2)$ \\
\hline Female & $4(30.8)$ \\
\hline \multicolumn{2}{|l|}{ ECOG PS } \\
\hline One & $9(69.2)$ \\
\hline Two & $4(30.8)$ \\
\hline \multicolumn{2}{|c|}{ Sidedness of the primary tumor } \\
\hline Right & $3(23.1)$ \\
\hline Left & $10(76.9)$ \\
\hline \multicolumn{2}{|c|}{ Number of organs involved } \\
\hline Median & 1 \\
\hline Range & $(1-2)$ \\
\hline One & $8(61.5)$ \\
\hline Greater than one & $5(38.5)$ \\
\hline \multicolumn{2}{|l|}{ Site of metastasis } \\
\hline Liver & $5(38.5)$ \\
\hline Lung & $1(7.7)$ \\
\hline LNs & $6(46.2)$ \\
\hline Peritoneum & $5(38.5)$ \\
\hline \multicolumn{2}{|l|}{ KRAS gene mutation } \\
\hline Mutant & $7(53.8)$ \\
\hline Wild-type & $5(38.5)$ \\
\hline Unknown & $1(7.7)$ \\
\hline \multicolumn{2}{|c|}{ Best response to XELOXIRI/A } \\
\hline$C R$ & $1(7.7)$ \\
\hline PR & $10(76.9)$ \\
\hline SD & $2(15.4)$ \\
\hline \multicolumn{2}{|c|}{ Surgical resection margin } \\
\hline RO & $10(76.9)$ \\
\hline R1 & $3(23.1)$ \\
\hline
\end{tabular}

IQR interquartile range; XELOXIRI/A xeloda, oxaliplatin, irinotecan, and avastin; ECOGPS Eastern Cooperative Oncology Group Performance Status; $C R$ complete response; $P R$ partial response; $S D$ stable disease; Primary primary tumor resection

for response for the following reasons: 4 withdrew consent, 2 were discontinued because of grade 4 toxicity, and 2 died before evaluation. Seven (15.5\%) of the evaluable patients had a tumor shrinkage of $\geq 40 \%$ [22]. Two of the thirteen patients who underwent surgical resection achieved complete pathological response (pCR).

With a median follow-up duration of 89 months, the median PFS for the whole group was 16.1 months [95\% confidence interval (CI) 9.1-20] and OS was 28.2 months (95\% CI 22.5-53.3) (Figs. 1 and 2).

The PFS for the surgery group was 18.9 months $(95 \%$ CI 12.6-not reached) compared to 9.6 months (95\% CI 7.0-18.3) for those who did not have surgery, log-rank $p$ $=0.0165$. The OS for both groups was not reached $(95 \%$ CI 53.3-not reached) and 23.2 months (95\% CI $17.0-$ 28.4) respectively, log-rank $p=0.0006$ ) (Figs. 3 and 4). Five-year PFS and OS for the surgery group were $46.2 \%$ and $67.6 \%$ compared to $15.4 \%$ and $3 \%$ in the nonsurgical group respectively.

The toxicity and adverse events of the triplet regimen have been published earlier [20].

\section{Discussion}

Surgical resection of metastatic disease of colorectal cancer has been shown in many trials to result in long-term disease-free and overall survival [11-15] and represents the only curative modality in this group of patients. The addition of targeted therapy to doublet chemotherapy regimens, in particular anti-EGFR therapy, has improved the resectability in patients with RAS wild-type phenotype with R0 resection ranging from 11.8 to $30.8 \%$ [17, 23, 24]. Triplet chemotherapy has also shown to increase the resectability rate in patients with unselected RAS phenotype. In a meta-analysis of 4 randomized trials with 1013 patients comparing triplet vs doublets regimens [25], the triplet chemotherapy did increase the R0 resectability with relative risk (RR) of 1.41 (95\% CI 1.07-1.85). Liver R0 resection rate also increased with RR of 2.28 (95\% CI 1.34-3.89). In this meta-analysis, the OLIVIA trial enrolled patients with only liver-limited disease (LLD) with higher response rate of $81 \%$ for the FOLFOXIRI-BEV vs $62 \%$ for FOLFOX-BEV. The overall resection rate was $61 \%$ vs $49 \%$, and the R0 resection rates were $41 \%$ vs $23 \%$ respectively [10]. The R0 resection rate for the TRIBE trial was 15\% [8]. The other 2 trials in the metaanalysis were the CHARTA which was published in an abstract form and the STEAM trial which reported liver resection rate of $17.2 \%$ [26, 27].

A pooled analysis published in 2017 of 11 trials with 889 patients utilizing FOLFOXIRI-Bevacizumab showed an overall resection rate of $39.1 \%$ (95\% CI $26.9-52.8 \%$ ) with an R0 resection rate of $28.1 \%$ (95\% CI 18.1-40.8\%) [28]. Out of those trials, three were all LLD while the mean incidence of LLD in the other 7 trials was 35.9\% (range 18-52\%). One trial did not report the percentage of LLD. The mean resectability rate in the 3 trials reporting non-LLD was $24.7 \%$ (range $15-32 \%$ ).

The patient population in our trial constitutes a highrisk group with $21 \%$ performance status of $2,11 \%$ with prior adjuvant chemotherapy, 37\% KRAS mutant, and $58 \%$ multiple sites of metastasis. Five patients $(9.4 \%)$ underwent liver resection (3 with resection of the primary), 5 (9.4\%) had cytoreductive surgery plus HIPEC as 
Table 3 Patients' characteristics in surgical and non-surgical groups

\begin{tabular}{llll}
\hline Item & Surgical resection & No surgical resection & $p$ value \\
\hline Median age & $50.5($ IQR 41-57) & $54($ IQR 43-59) & 0.8 \\
Males \% & $9(69.3 \%)$ & $18(47.2 \%)$ & 0.2 \\
Median performance status & $1($ IQR 0.5-1) & $1($ IQR 1-2) & 0.3 \\
$\%$ right-sided primary & $3(23.1 \%)$ & $8(21.1 \%)$ & 0.8 \\
Median number metastatic site & $1($ IQR 1-2) & $2($ IQR 1-3) & 0.09 \\
$\%$ mutant KRAS & $7(53.8 \%)$ & $13(34.2 \%)$ & 0.3 \\
$\%$ best response & $11(84.6 \%)$ & $18(56.2 \%)$ & 0.3 \\
\hline
\end{tabular}

$I Q R$ interquartile range

part of their surgical management, and one had pulmonary metastatectomy. The remaining two had resection of initially unresectable primary tumor.

The median number of chemotherapy cycles in our patients was 9 (range 2-20). This goes with the prior finding of higher probability of secondary surgery with increasing number of cycles [29]. Despite relatively high number of chemotherapy cycles in the patients who underwent surgical resection, only 2 had major surgical complications with one developing pancreatic leakage and the other developing hospital-acquired pneumonia. This in contrast to the previous report by Karoui et al. where $54 \%$ of the patients who had equal or more than 6 cycles and underwent major liver surgery had surgical complications compared to $19 \%$ in those who had received less than 6 cycles $(p=0.047)$ [30]. Our lower rate of surgical complications is likely secondary to refinement of the surgical procedures and postoperative management.

It is likely that the addition of bevacizumab to intensive chemotherapy regimens does not increase the rate of resectability since this had not been proven elsewhere. On the other hand, the addition of antibody to epidermal growth factor receptor (EGFR) has shown an increase in the response and resectability rates at least in patients with unresctable LLD. In the UNICANCER PRODIGE 14-ACCORD 21 (METHEP-2) trial, the ORR for FOLFORINOX-Bevacizumab was 58\% compared to $83 \%$ in patients who received FOLFORINOXCetuximab. The R0/R1 resection rates were $54 \%$ vs $63 \%$ respectively [31].

The relatively high resection rate with our triplet regimen resulted in an encouraging 5-year PFS of $46.2 \%$ and OS of $67.5 \%$. This clearly indicates the benefit of

Table 4 Surgical procedures after the triplet chemotherapy regimen

\begin{tabular}{|c|c|c|c|c|}
\hline No. & Surgical procedure & $\begin{array}{l}\text { No. of chemotherapy cycles } \\
\text { prior to surgery }\end{array}$ & $\begin{array}{l}\text { Hospital stay } \\
\text { (days) }\end{array}$ & $\begin{array}{l}\text { Major surgical } \\
\text { complications }\end{array}$ \\
\hline 1 & $\begin{array}{l}\text { Cytoreductive surgery [subtotal colectomy + bilateral oophorectomy + } \\
\text { cholecystectomy] + HIPEC }\end{array}$ & 8 & 30 & \\
\hline 2 & $\begin{array}{l}\text { Cytoreductive surgery [abdominal wall resection + left hemicolectomy + } \\
\text { appendicectomy] + HIPEC }\end{array}$ & 13 & 13 & Pancreatic leakage \\
\hline 3 & $\begin{array}{l}\text { Cytoreductive surgery [extended left hemicolectomy + distal pancreatectomy } \\
+ \text { small bowl resection] + HIPEC }\end{array}$ & 12 & 29 & \\
\hline 4 & Segmental liver resection & 10 & 7 & \\
\hline 5 & $\begin{array}{l}\text { Cytoreductive surgery [subtotal colectomy + appendicectomy + } \\
\text { cholecystectomy + splenectomy] + HIPEC }\end{array}$ & 6 & 15 & \\
\hline 6 & Bilateral pulmonary metastatectomy & 2 & 12 & \\
\hline 7 & High anterior resection & 7 & 9 & \\
\hline 8 & $\begin{array}{l}\text { Cytoreductive surgery [extended left hemicolectomy + splenectomy + } \\
\text { appendicectomy }+ \text { cholecystectomy] }+ \text { HIPEC }\end{array}$ & 9 & 17 & \\
\hline 9 & Anterior resection + liver metastatectomy & 16 & 18 & \\
\hline 10 & Total proctocolectomy & 7 & 13 & \\
\hline 11 & Anterior resection + liver metastatectomy & 18 & 28 & $\begin{array}{l}\text { Hospital-acquired } \\
\text { pneumonia }\end{array}$ \\
\hline 12 & Sigmoidectomy + liver metastatectomy & 20 & 16 & \\
\hline 13 & Liver metastatectomy & 9 & 14 & \\
\hline
\end{tabular}




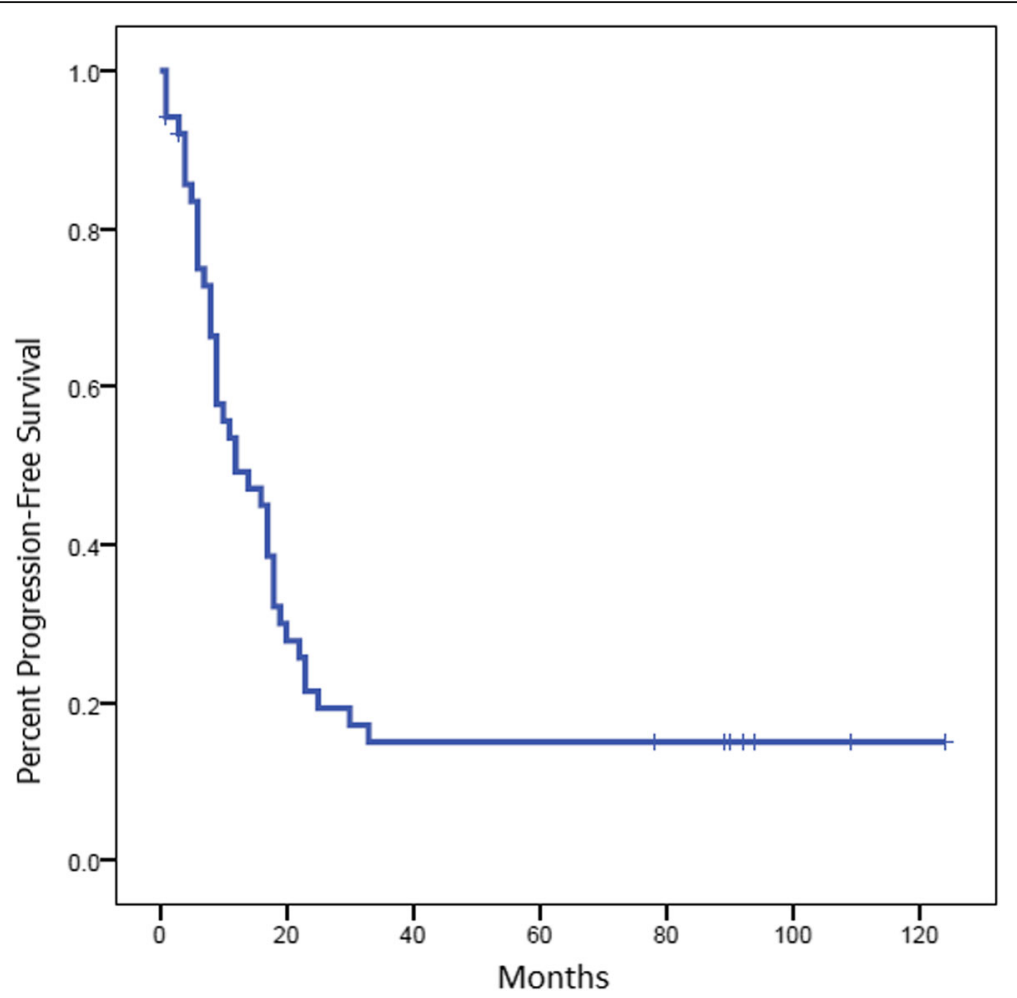

Fig. 1 Progression-free survival (PFS) of the whole group

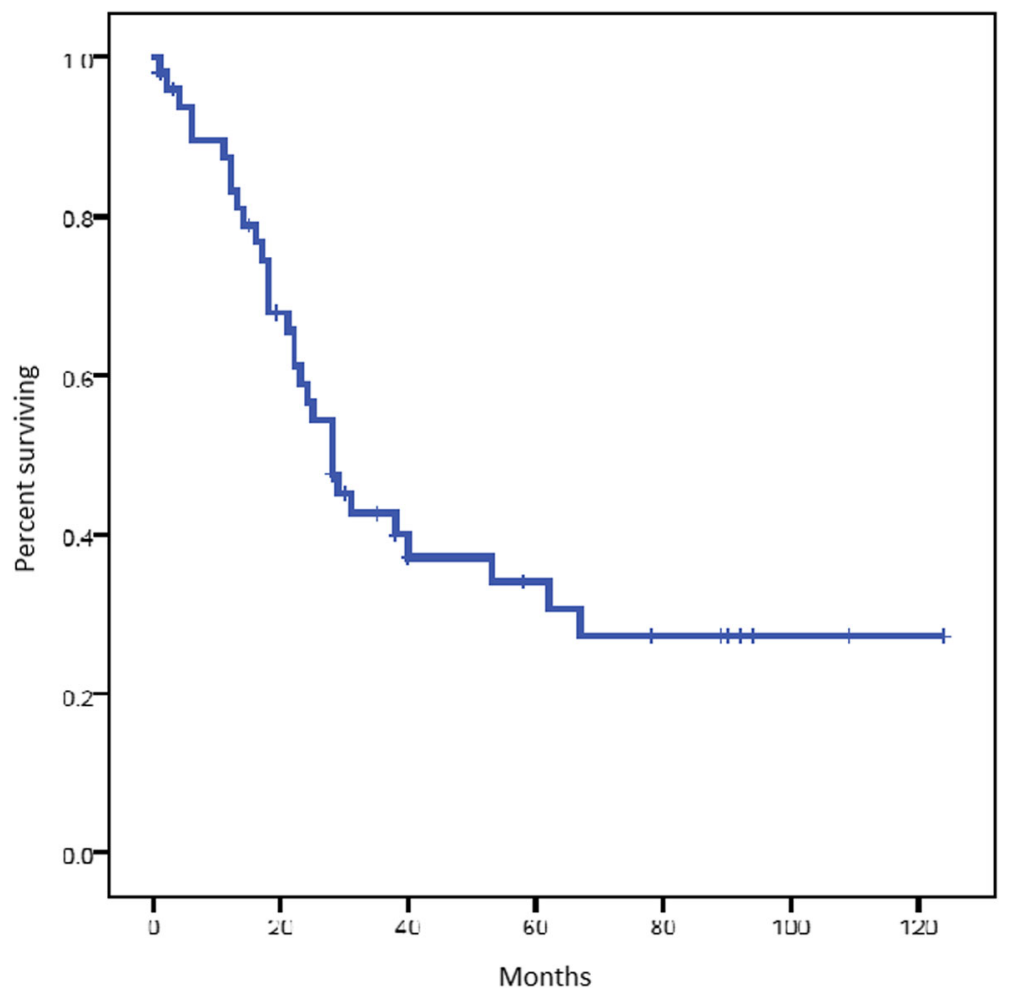

Fig. 2 Overall survival (OS) of the whole group 


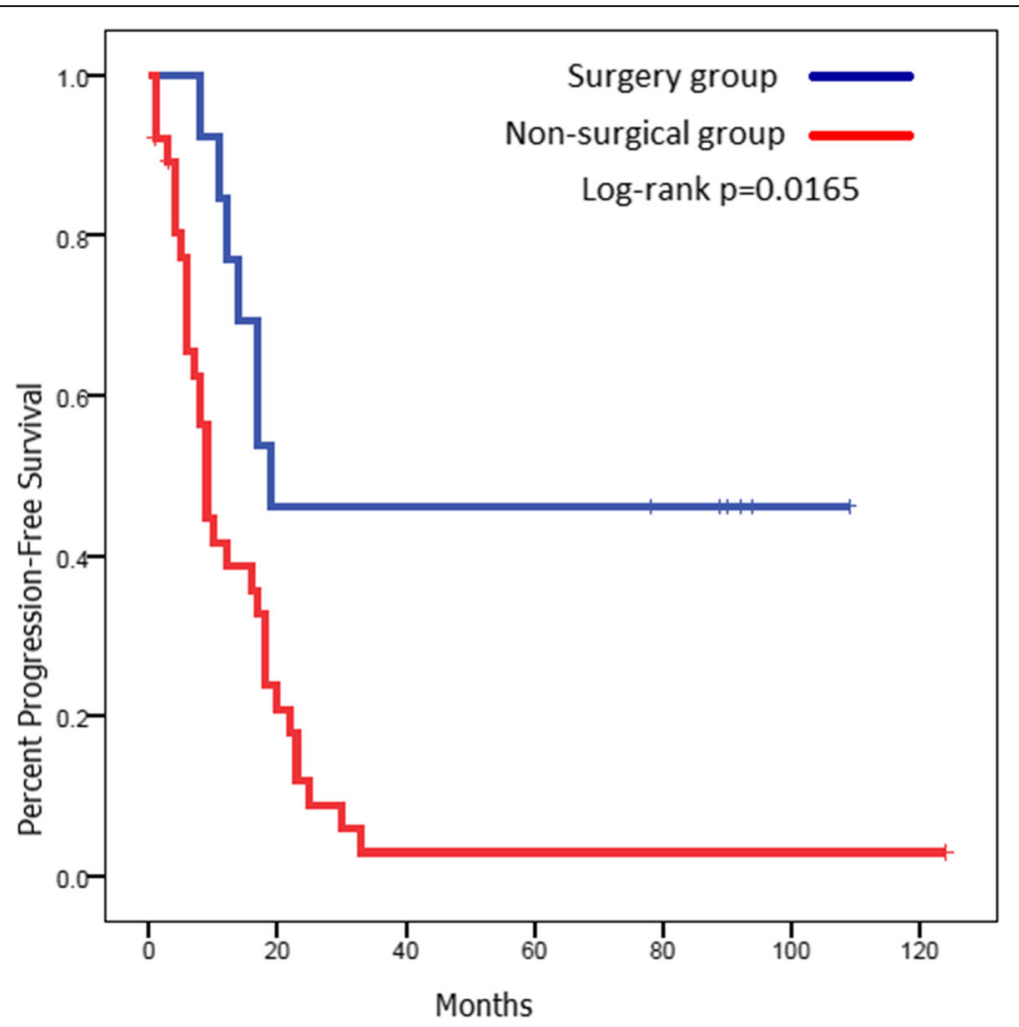

Fig. 3 Progression-free survival (PFS) of the surgical vs the non-surgical groups

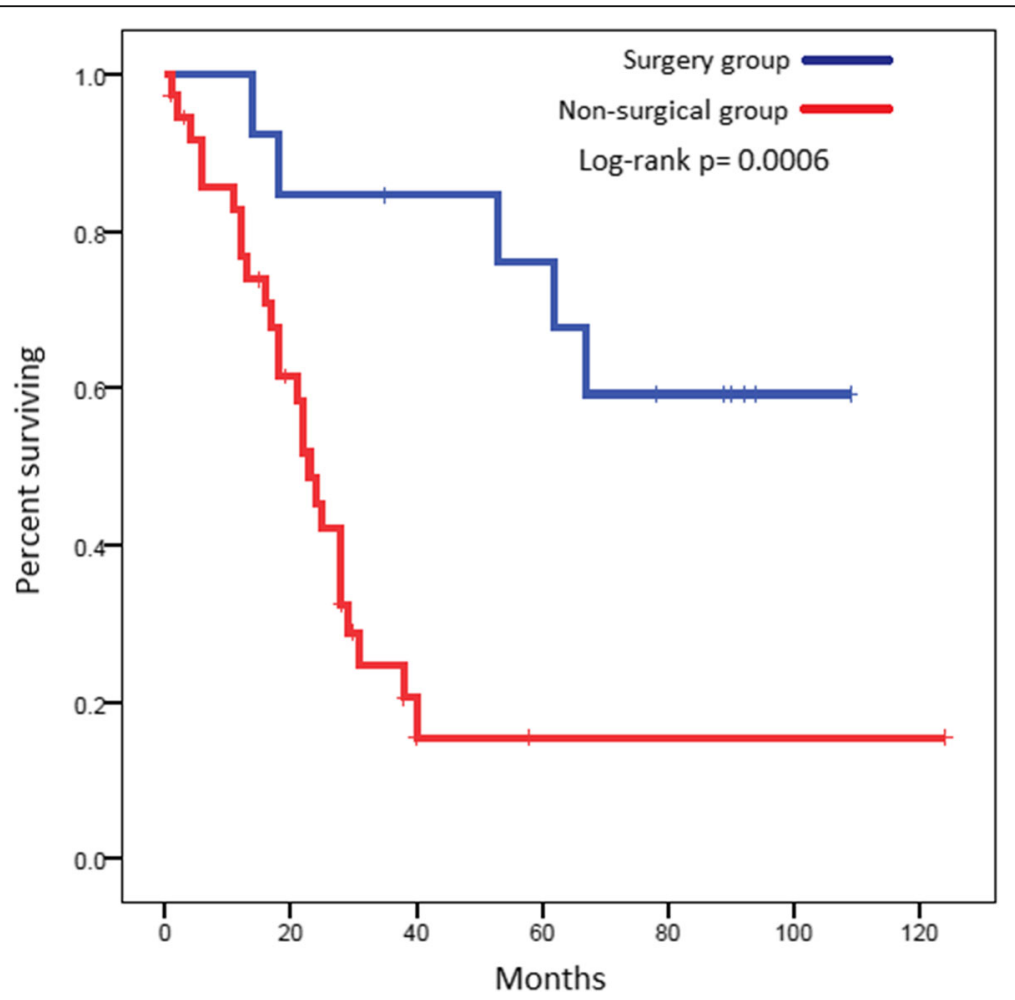

Fig. 4 Overall survival (OS) of the surgical vs the non-surgical groups 
combining intensive chemotherapy and surgery (for those who became resectable) as compared to chemotherapy alone where the 5-year PFS and OS were much lower at $3 \%$ and $15.4 \%$ respectively. This should be balanced against the higher toxicity rates of triplet regimens. The grades $3 / 4$ toxicities of our regimen with oral capecitabine (reported earlier) [20] were unfortunately higher than infusional 5-fluorouracil regimens.

Our study had several limitations including a small number of patients, being a single-institution study, and post hoc nature of the analysis.

In conclusion, triplet chemotherapy regimens in patients with initially unresectable metastatic colorectal cancer yield a high rate of resection which results in long-term progression-free and overall survival in the resected group of patients. All eligible patients for such therapy should be given the benefit of this intensified chemotherapy regimens.

\section{Abbreviations}

CRC: Colorectal cancer; ECOG: Eastern Cooperative Group Performance Status; PFS: Progression-free survival; OS: Overall survival; Cl: Confidence interval; HIPEC: Hyperthermic intraperitoneal chemotherapy; RECIST: Response evaluation criteria in solid tumors; ANC: Absolute neutrophil count; IRB: Institutional review board; LLD: Liver-limited disease; CR: Complete response; PR: Partial response; ORR: Overall response rate; SD: Stable disease; pCR: Pathological complete response; RR: Relative risk

\section{Acknowledgements}

We thank the patients for their participation, help, and time in assisting with this study.

\section{Authors' contributions}

Mahmoud Elshenawy: data collection, analysis of the data, and manuscript writing. Ahmed Badran: data collection, analysis of the data, and manuscript writing. Ali Aljubran: data collection and analysis of the data. Ahmed Alzahrani: data collection and analysis of the data. M. Shahzad Rauf: data collection and analysis of the data. Abdelmonem Eldali: statistical analysis. Shouki Bazarbashi: design of the study, data collection, analysis of data, and manuscript writing. The author(s) read and approved the final manuscript.

\section{Funding}

No funding was received for this study.

\section{Availability of data and materials}

The datasets used and analyzed during the current study are available from the corresponding author upon any reasonable request.

\section{Ethics approval and consent to participate}

This trial was carried out according to the good clinical practice and the Declaration of Helsinki. All patients signed an informed written consent detailing the investigational nature of the trial. The study was approved by the hospital's institutional review board (IRB), RAC\# 2081-068. Patients' confidentiality was maintained throughout the study. The trial was registered at clinicaltrials.gov (NCT 01311050).

\section{Consent for publication}

This study is accepted as a poster presentation at the ESMO 22nd World Congress on Gastrointestinal Cancer. The manuscript has not been published or presented elsewhere in part or in entirety and is not under consideration by another journal.

\section{Competing interests}

We have no conflicts of interest to declare.

\section{Author details}

${ }^{1}$ Medical Oncology Section, Oncology Centre, King Faisal Specialist Hospital and Research Centre, PO Box 3354, Riyadh 11211, Saudi Arabia. ${ }^{2}$ Clinical Oncology Department, Faculty of Medicine, Menoufia University, Shebin El Kom 32511, Egypt. ${ }^{3}$ Clinical Oncology Department, Faculty of Medicine, Ain Shams University, Cairo 11591, Egypt. ${ }^{4}$ Department of Biostatistics, Epidemiology and Scientific computing, King Faisal Specialist Hospital and Research Centre, PO Box 3354, Riyadh 11211, Saudi Arabia.

Received: 17 May 2020 Accepted: 23 June 2020

Published online: 08 July 2020

\section{References}

1. Bray F, Ferlay J, Soerjomataram I, Siegel RL, Torre LA, Jemal A. Global cancer statistics 2018: GLOBOCAN estimates of incidence and mortality worldwide for 36 cancers in 185 countries. CA Cancer J Clin. 2018;68:394-424.

2. Segal NH, Saltz LB. Evolving treatment of advanced colon cancer. Annu Rev Med. 2009;60:207-19 Available from: http://www.ncbi.nlm.nih.gov/ pubmed/19630571.

3. De Greef K, Rolfo C, Russo A, Chapelle T, Bronte G, Passiglia F, et al. Multisciplinary management of patients with liver metastasis from colorectal cancer. World J Gastroenterol. 2016;22:7215-25 Available from: http://www. ncbi.nlm.nih.gov/pubmed/27621569.

4. Venook AP, Niedzwiecki D, Lenz HJ, Innocenti F, Fruth B, Meyerhardt JA, et al. Effect of first-line chemotherapy combined with cetuximab or bevacizumab on overall survival in patients with KRAS wild-type advanced or metastatic colorectal cancer a randomized clinical trial. JAMA - J Am Med Assoc. 2017;317:2392-401.

5. Stintzing S, Fischer von weikersthal L, Decker T, Vehling-kaiser U, Jäger E, Heintges T, et al. FOLFIRI plus cetuximab versus FOLFIRI plus bevacizumab as first-line treatment for patients with metastatic colorectal cancersubgroup analysis of patients with KRAS: mutated tumours in the randomised German AlO study KRK-0306. Ann Oncol. 2012;23:1693-9.

6. Van Cutsem E, Köhne CH, Hitre E, Zaluski J, Chien CRC, Makhson A, et al. Cetuximab and chemotherapy as initial treatment for metastatic colorectal cancer. N Engl J Med. 2009;360:1408-17.

7. Van Cutsem E, Köhne CH, Láng I, Folprecht G, Nowacki MP, Cascinu S, et al. Cetuximab plus irinotecan, fluorouracil, and leucovorin as first-line treatment for metastatic colorectal cancer: updated analysis of overall survival according to tumor KRAS and BRAF mutation status. J Clin Oncol. 2011;29:2011-9.

8. Cremolini C, Loupakis F, Antoniotti C, Lupi C, Sensi E, Lonardi S, et al. FOLFOXIRI plus bevacizumab versus FOLFIRI plus bevacizumab as first-line treatment of patients with metastatic colorectal cancer: updated overall survival and molecular subgroup analyses of the open-label, phase 3 TRIBE study. Lancet Oncol. 2015;16:1306-15.

9. Falcone A, Ricci S, Brunetti I, Pfanner E, Allegrine G, Barbara C, et al. Phase III trial of infusional fluorouracil, leucovorin, oxaliplatin, and irinotecan (FOLFOXIRI) compared with infusional fluorouracil, leucovorin, and irinotecan (FOLFIRI) as first-line treatment for metastatic colorectal cancer: The gruppo oncologico nor. J Clin Oncol. 2007;25:1670-6.

10. Adam R, Bridgewater J, Chau I, Alfonso PG, Rivoire M, Lasserre S, et al. Randomised, phase 2 study (OLIVIA) of bevacizumab plus mFOLFOX6 or folfoxiri in patients with initially unresectable colorectal cancer liver metastases. Ann Oncol. 2013;24:iv21 Available from: https://linkinghub. elsevier.com/retrieve/pii/S0923753419545306.

11. Adam R, Wicherts DA, de Haas RJ, Ciacio O, Lévi F, Paule B, et al. Patients with initially unresectable colorectal liver metastases: is there a possibility of cure? J Clin Oncol. 2009;27:1829-35 Available from: http://ascopubs.org/ doi/10.1200/JCO.2008.19.9273.

12. Mayo SC, Pulitano C, Marques H, Lamelas J, Wolfgang CL, de Saussure W, et al. J Am Coll Surg. 2013;216:707-16 Available from: https://linkinghub. elsevier.com/retrieve/pii/S1072751512014342.

13. Sugarbaker PH. Cytoreductive surgery plus hyperthermic perioperative chemotherapy for selected patients with peritoneal metastases from colorectal cancer: a new standard of care or an experimental approach? Gastroenterol Res Pract. 2012;2012.

14. Cashin PH, Mahteme H, Spång N, Syk I, Frödin JE, Torkzad M, et al. Cytoreductive surgery and intraperitoneal chemotherapy versus systemic chemotherapy for colorectal peritoneal metastases: a randomised trial. Eur J Cancer. 2016;53:155-62. 
15. Lin EK, Hsieh MC, Chen CH, Lu YJ, Wu SY. Outcomes of cytoreductive surgery and hyperthermic intraperitoneal chemotherapy for colorectal cancer with peritoneal metastasis. Med (United States). 2016:95.

16. Ychou M, Rivoire M, Thezenas S, Quenet F, Delpero J-R, Rebischung C, et al. A randomized phase II trial of three intensified chemotherapy regimens in firstline treatment of colorectal cancer patients with initially unresectable or not optimally resectable liver metastases. The METHEP trial. Ann Surg Oncol. 2013; 20:4289-97 Available from: http:/www.ncbi.nlm.nih.gov/pubmed/23955585.

17. Folprecht G, Gruenberger T, Bechstein WO, Raab H-R, Lordick F, Hartmann $J$ T, et al. Tumour response and secondary resectability of colorectal liver metastases following neoadjuvant chemotherapy with cetuximab: the CELIM randomised phase 2 trial. Lancet Oncol. 2010;1 1:38-47 Available from: http://www.ncbi.nlm.nih.gov/pubmed/19942479.

18. Cremolini C, Marmorino F, Loupakis F, Masi G, Antoniotti C, Salvatore L, et al. TRIBE-2: a phase III, randomized, open-label, strategy trial in unresectable metastatic colorectal cancer patients by the GONO group. BMC Cancer. 2017;17:408 Available from: http://www.ncbi.nlm.nih.gov/ pubmed/28599628.

19. Souglakos J, Androulakis N, Syrigos K, Polyzos A, Ziras N, Athanasiadis A, et al. FOLFOXIRI (folinic acid, 5-fluorouracil, oxaliplatin and irinotecan) vs FOLFIRI (folinic acid, 5-fluorouracil and irinotecan) as first-line treatment in metastatic colorectal cancer (MCC): a multicentre randomised phase III trial from the Hellenic Oncolog. Br J Cancer. 2006;94:798-805 Available from: http://www.ncbi.nlm.nih.gov/pubmed/16508637.

20. Bazarbashi S, Aljubran A, Alzahrani A, Mohieldin A, Soudy H, Shoukri M. Phase I/II trial of capecitabine, oxaliplatin, and irinotecan in combination with bevacizumab in first line treatment of metastatic colorectal cancer. Cancer Med. 2015;4:1505-13.

21. Eisenhauer EA, Therasse P, Bogaerts J, Schwartz LH, Sargent D, Ford R, et al. New response evaluation criteria in solid tumours: revised RECIST guideline (version 1.1). Eur J Cancer. 2009;45:228-47 Available from: http://www.ncbi. nlm.nih.gov/pubmed/19097774.

22. Shouki B, Ali AJ, Ahmad AZ, Hussein S, Mohammed S. P-0243 * Deep responders represent a group with excellent survival in patients with metastatic colorectal cancer (MCRC) treated with triplet chemotherapy regimens (TCR). Ann Oncol. 2014;25:ii90 Available from: https://academic. oup.com/annonc/article-lookup/doi/10.1093/annonc/mdu165.238.

23. Douillard J-Y, Siena S, Peeters M, Koukakis R, Terwey J-H, Tabernero J. Impact of early tumour shrinkage and resection on outcomes in patients with wild-type RAS metastatic colorectal cancer. Eur J Cancer. 2015;51:123142 Available from: http://www.ncbi.nlm.nih.gov/pubmed/25956209.

24. Ye L-C, Liu T-S, Ren L, Wei Y, Zhu D-X, Zai S-Y, et al. Randomized controlled trial of cetuximab plus chemotherapy for patients with KRAS wild-type unresectable colorectal liver-limited metastases. J Clin Oncol. 2013;31:19318 Available from: http://www.ncbi.nlm.nih.gov/pubmed/23569301.

25. Shui L, Wu YS, Lin H, Shui P, Sun Q, Chen X. Triplet chemotherapy (FOLFOXIRI) plus bevacizumab versus doublet chemotherapy (FOLFOX/ FOLFIRI) plus bevacizumab in conversion therapy for metastatic colorectal cancer: a meta-analysis. Cell Physiol Biochem. 2018;48:1870-81.

26. Schmoll H-J, Meinert FM, Cygon F, Garlipp B, Junghanss C, Leithäuser M, et al. "CHARTA": FOLFOX/Bevacizumab vs. FOLFOXIRI/Bevacizumab in advanced colorectal cancer-final results, prognostic and potentially predictive factors from the randomized phase II trial of the AlO. I Clin Oncol. 2017;35:3533 Available from: http://ascopubs.org/doi/10.1200/JCO.2 017.35.15_suppl.3533.

27. Hurwitz HI, Tan BR, Reeves JA, Xiong H, Somer B, Lenz H-J, et al. Phase II randomized trial of sequential or concurrent FOLFOXIRI-bevacizumab versus FOLFOX-bevacizumab for metastatic colorectal cancer (STEAM). Oncologist. 2019; 24:921-32 Available from: http://www.ncbi.nlm.nih.gov/pubmed/30552157.

28. Tomasello G, Petrelli F, Ghidini M, Russo A, Passalacqua R, Barni S. FOLFOXIRI plus bevacizumab as conversion therapy for patients with initially unresectable metastatic colorectal cancer: a systematic review and pooled analysis. JAMA Oncol. 2017;3:1-6.

29. Tomasello G, Petrelli F, Ghidini M, Russo A, Passalacqua R, Barni S. FOLFOXIR plus bevacizumab as conversion therapy for patients with initially unresectable metastatic colorectal cancer: a systematic review and pooled analysis. JAMA Oncol. 2017;3:3-8.

30. Karoui M, Penna C, Amin-Hashem M, Mitry E, Benoist S, Franc B, et al. Influence of preoperative chemotherapy on the risk of major hepatectomy for colorectal liver metastases. Ann Surg. 2006;243:1-7 Available from: http://www.ncbi.nlm.nih.gov/pubmed/16371728.
31. Ychou M, Rivoire M, Thezenas S, Guimbaud R, Ghiringhelli F, Mercier Blas A, et al. Induction chemotherapy (CT) with FOLFIRINOX or FOLFOX/FOLFIRI, plus cetuximab (CET) or bevacizumab (BEV) (by RAS status), in patients (pts) with primarily unresectable colorectal liver metastases (CRLM): results of the randomized UNICANCER PRODIGE 14-ACCO. J Clin Oncol. 2018;36:3535 Available from: http://ascopubs.org/doi/10.1200/JCO.2018.36.15_suppl.3535.

\section{Publisher's Note}

Springer Nature remains neutral with regard to jurisdictional claims in published maps and institutional affiliations.
Ready to submit your research? Choose BMC and benefit from:

- fast, convenient online submission

- thorough peer review by experienced researchers in your field

- rapid publication on acceptance

- support for research data, including large and complex data types

- gold Open Access which fosters wider collaboration and increased citations

- maximum visibility for your research: over $100 \mathrm{M}$ website views per year

At BMC, research is always in progress.

Learn more biomedcentral.com/submissions 